\title{
Systematic Evaluation of Magnetic Resonance Imaging and Spectroscopy Techniques for Imaging a Transgenic Model of Alzheimer's Disease (AßPP/PS1)
}

\author{
Noemí Esteras ${ }^{\mathrm{a}}$, Carolina Alquézar ${ }^{\mathrm{a}, \mathrm{f}}$, Fernando Bartoloméa $^{\mathrm{a}}$, Desiree Antequera ${ }^{\mathrm{b}}$, Laura Barrios ${ }^{\mathrm{c}}$, \\ Eva Carro ${ }^{\mathrm{b}, \mathrm{e}}$, Sebastián Cerdán ${ }^{\mathrm{d}}$ and Ángeles Martín-Requero ${ }^{\mathrm{a}, \mathrm{f}, *}$ \\ ${ }^{a}$ Centro de Investigaciones Biológicas (CSIC), Madrid, Spain \\ ${ }^{\mathrm{b}}$ Instituto de Investigación, Grupo de Neurociencias, Hospital Doce de Octubre, Madrid, Spain \\ ${ }^{\mathrm{c}}$ Centro Técnico de Informática (CSIC), Madrid, Spain \\ dinstituto de Investigaciones Biomédicas “Alberto Sols” CSIC/UAM, Madrid, Spain

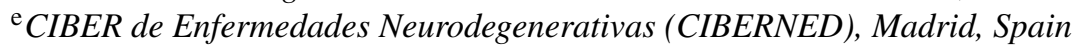 \\ ${ }^{\mathrm{f}}$ CIBER de Enfermedades Raras (CIBERER), Madrid, Spain
}

Accepted 7 February 2012

\begin{abstract}
Murine models of Alzheimer's disease (AD) provide means to detect and follow biomarker changes similar to those observed in humans. Non-invasive biomarkers, such as those provided by magnetic resonance imaging (MRI) and spectroscopy (MRS) methods are highly desirable, however, systematic studies of in vivo MRI/MRS methods to characterize the cerebral morphology and metabolic pattern of these mice remain scarce. We investigated sixteen consecutive slices from the brain of wild-type and AßPP/PS1 mice, obtaining a collection of $\mathrm{T}_{2}$-weighted, diffusion weighted and magnetization transfer weighted images as well as ${ }^{1} \mathrm{H}$ PRESS spectra from the cortical and subcortical areas. Compared to controls, AßPP/PS1 mice show significant regional hyperintensities in $\mathrm{T}_{2}$-weighted images of the cerebral cortex, significant ventricular enlargement, and decreased hippocampal area and fractional magnetization transfer. MRS demonstrated an increase in the ratio of choline (Cho) to creatine $(\mathrm{Cr})$ in the cortical and subcortical areas of the transgenic animals. A logistic regression classifier was implemented considering all parameters investigated, and revealed the most characteristic changes and allowed for the correct classification of control and AßPP/PS1 mice. In summary, the present results provide a useful frame to evaluate optimal MRI/MRS biomarkers for the characterization of AD models, potentially applicable in drug discovery processes, because of their non-invasive and repeatable nature in longitudinal studies.
\end{abstract}

Keywords: ADC maps, Alzheimer's disease, MRI, MRS, MT maps, $\mathrm{T}_{2}$-weighting, transgenic mice, ventricle enlargement

\section{INTRODUCTION}

Alzheimer's disease (AD) is a devastating neurodegenerative disorder affecting more than 20 million

\footnotetext{
*Correspondence to: Dr. Ángeles Martín-Requero, Centro de Investigaciones Biológicas (CSIC), Ramiro de Maeztu 9, 28040 Madrid, Spain. Tel.: +3491 8373112; Fax: +3491 5360432; E-mail: amrequero@cib.csic.es.
}

people worldwide [1]. Key histopathological features include amyloid- $\beta(A \beta)$-containing senile plaques and neurofibrillary tangles (NFTs), along with neuronal loss in selected brain areas [2]. Presently, a definitive diagnosis of $\mathrm{AD}$ is possible only by examining brain tissue after death and requires anatomical evidence for the existence of plaques and NFTs. However, advances in clinical diagnostic tools, including brain imaging 
techniques and novel biomarkers, could potentially help identify 'at risk' subjects prior to the presence of any cognitive deterioration. Moreover, imaging techniques and/or specific biomarkers for $\mathrm{AD}$ hold great promise concerning monitoring disease status and treatment response.

A small proportion of AD patients expresses mutations in the amyloid- $\beta$ precursor protein $(\mathrm{A} \beta \mathrm{PP})$ and presenilin (PS1 and PS2) proteins or overexpress A $\beta P P$ itself [3]. These 'familial' AD patients suffer from earlier and more rapid, but otherwise identical, amyloid deposition, brain atrophy, and cognitive decline than late-onset $\mathrm{AD}$ patients, who form the majority of cases. These human mutations have provided the means to generate a number of transgenic mice differing in the number and type of A $\beta P P$ and PS mutations expressed, as well as in the promoters that govern transgene expression (for reviews, see [4, 5]). Although none of these models fully replicate the human disease, they have provided valuable insights into disease mechanisms [6]. Therefore, it becomes relevant to apply technologies and biomarkers similar to those used in humans for the follow-up of AD animal models, particularly for the clarification of mechanisms and for the screening and validation of new candidate treatments.

Magnetic resonance imaging (MRI) and spectroscopy (MRS) methodologies provide comprehensive and non-invasive information of cerebral morphology and metabolism. In particular, MRI has been most widely used in $\mathrm{AD}$ research to visualize the onset and advance of neurodegeneration, with the goal of identifying particular brain regions that can predict the likelihood of progressing from mild cognitive impairment (MCI) to dementia [7-12]. MR technologies have also been used in normal and genetically engineered mice [13-17]. However, many of these studies have relied in the segmentation of preselected regions-of-interest (ROI), known to become severely degenerated in AD [18], neglecting the potential of the MR method to provide more comprehensive information on the whole brain. Moreover, no systematic assessment of the relative efficacy of different MRI/MRS methods, including anatomical $\mathrm{T}_{2}$-weighted, diffusion weighted, magnetization transfer (MT) imaging or the ${ }^{1} \mathrm{H}$ spectroscopy methods in the evaluation of $\mathrm{AD}$ is currently available.

On these grounds, we present here a study combining a variety of in vivo MRI/MRS measurements through the complete brain of A $\beta P P / P S 1$ mice and wild-type littermates, to evaluate the relative potential of each approach in the characterization of the
AD phenotype. To this end, we have implemented a logistic regression algorithm to identify the MRI/MRS parameter or combination of parameters that best discriminate between controls and a transgenic mouse model of AD. Moreover, since previous studies [19] indicated that in vivo imaging can predict levels of neurogenesis in the living mice, we investigated whether anatomical changes in the hippocampus could compromise the proliferation of neuronal precursors in this region. For the present studies, we chose $\mathrm{A} \beta \mathrm{PP} / \mathrm{PS} 1$ mice as the transgenic model of AD. These mice are a cross of the $\mathrm{Tg} 2576$ (over-expressing human A $\beta P P$ (hA $\beta P P)$ 695, with the double mutation KM670/671NL), and mutant PS1 (M146 L) mice. This murine model of AD typically expresses sufficiently high levels of hA $\beta P P$ and $A \beta$ to insure amyloid deposition [20]. $A \beta$ is deposited progressively in the brain of these mice beginning at eight weeks of age [21], associated with extensive dystrophy of neurites. In addition, these mice, carrying mutations in the two AD proteins, depict signs of apoptotic cell death in the hippocampus and cerebral cortex of six-nine month-old animals $[22,23]$.

We report that $\mathrm{A} \beta \mathrm{PP} / \mathrm{PS} 1$ mice depict enlarged ventricles and decreased hippocampal volume, together with decreased MT, enhanced neurogenesis, and increases in the choline (Cho) signal in the spectra of the cerebral cortex and subcortical area. Taken together, our results indicate that the Cho/creatine $(\mathrm{Cr})$ ratio, as measured in the subcortical region provides an optimal biomarker of disease status, fully discriminating between control and A $\beta P P / P S 1$ mice that are twelve months of age. In addition, our results suggest that MRI/MRS technologies provide a robust and convenient tool for the evaluation of AD disease status and disease-modifying therapies in the A $\beta P P / P S 1$ mouse model.

\section{METHODS}

\section{Animal model and experimental design}

All procedures with animals were specifically approved by the 'Ethics Committee for Animal Experimentation' of the Center for Biological Research (CIB, CSIC), and carried out in accordance with the protocols issued which followed National (normative 1201/2005) and International recommendations (normative 86/609 from the European Communities Council). Adequate measures were taken to minimize pain or discomfort of animals. Double-transgenic AßPP/PS1 male mice ( $n=7,12$ months of age), a 
cross of the Tg2576 (overexpressing human-A $\beta P P 695$ with double mutations at KM670/671NL) and mutant PS1 (M146L) mice, based on the C57BJ6 phenotype, were used as a model of AD amyloidosis [24]. Nontransgenic C57BJ6 male littermates $(n=8)$ were used as controls.

Preanesthesia was induced, before MR examinations, by administering a mixture of $97 \% / 3 \%$ oxygen/isofluorane with the animal placed in the interior of a plexiglass chamber. The animal was then positioned in the NMR cradle, transferred to the center of the magnetic field and the anesthesia maintained throughout the imaging procedure by administering a mixture of $98 \% / 2 \%$ oxygen/isofluorane $(1 \mathrm{~mL} / \mathrm{min})$ through a nose-cap. Animal temperature was maintained at $37^{\circ} \mathrm{C}$ with a water heated pad adapted to the cradle. The respiratory rate of the animals was monitored using a Biotrig physiological monitor (Bruker Medical Gmbh, Ettlingen, Germany).

\section{MRI/MRS methods}

The MRI experiments were performed on a Bruker Pharmascan 7.0-T $16 \mathrm{~cm}$ horizontal-bore system (Bruker Medical Gmbh, Ettlingen, Germany), equipped with a $23 \mathrm{~mm}$ mouse head ${ }^{1} \mathrm{H}$ selective birdcage resonator and a $90 \mathrm{~mm}$ diameter gradient insert (maximum intensity $30 \mathrm{G} / \mathrm{cm}$ ). All data were acquired using a Hewlett-Packard console running Paravision software v 5.1 operating under a Linux environment.

$\mathrm{T}_{2}$-weighted $\left(\mathrm{T}_{2}-\mathrm{W}\right)$ spin-echo anatomical images used a rapid acquisition method with relaxation enhancement (RARE) in axial orientations with the following parameters: $\mathrm{TR}=2500 \mathrm{~ms}, \mathrm{TE}=60 \mathrm{~ms}$, RARE factor $=8, \quad A v=6, \quad F O V=2.3 \mathrm{~cm}$, acquisition matrix $=256 \times 256$, slice thickness $=1.00 \mathrm{~mm}$ and number of slices $=16$. Image Processing was performed with the ImageJ Package (Wayne Rasband, National Institutes of Health, USA, http:// rsbweb.nih.gov/ij/). Ventricular and hippocampus areas determined in each $\mathrm{T}_{2}$-weighted slice were normalized to the corresponding total brain area, and compared in control and A $\beta P P / P S 1$ mice. Apparent diffusion coefficient (ADC) maps were obtained from diffusion weighted images acquired with increasing b values, essentially as previously described [25]. The following parameters were used: $\mathrm{TR}=3000 \mathrm{~ms}$, $\mathrm{TE}=51 \mathrm{~ms}, \mathrm{Av}=3$, diffusion gradient duration $=4 \mathrm{~ms}$, diffusion gradient separation $=16 \mathrm{~ms}$, diffusion gradient direction: left-right, FOV: $3.8 \mathrm{~cm}$, acquisition matrix $=128 \times 128$, b values $=100,200,300,500,800$, and $1200 \mathrm{~s} / \mathrm{mm}^{2}$. The ADC maps were calculated by fitting non-linearly the function $\mathrm{I}_{\mathrm{b}}=\mathrm{I}_{\mathrm{o}} \mathrm{e}^{-A D C \cdot \mathrm{b}}$ to every pixel where: $\mathrm{I}_{\mathrm{b}}=$ signal intensity at value $\mathrm{b}, \mathrm{I}_{\mathrm{o}}=$ Signal intensity for $b=0, b=$ diffusion weighting factor and $\mathrm{ADC}=$ apparent diffusion coefficient.

MT maps were acquired with a multi-slice multi-echo sequence in axial orientation and the following parameters: $\mathrm{TR}=2500 \mathrm{~ms}, \mathrm{TE}=9.8 \mathrm{~ms}$, $\mathrm{Av}=1, \mathrm{FOV}=2.0 \mathrm{~cm}$, acquisition matrix $=128 \times 128$, after applying (Mt) or not (Mo) a magnetization transfer saturation pulse at $8.0 \mathrm{ppm} . \mathrm{M}(\mathrm{t}) / \mathrm{M}(0)$ maps were prepared by dividing pixel by pixel the intensities of saturated and non-saturated images.

Pixel by pixel operations and non-linear fittings of diffusion data sets were performed using the homemade software My Map Analyzer, running under MatLab v7 in a LINUX based platform.

Images were registered and aligned using SPM software (Neuroimaging Informatics Tools and Resources Clearinghouse, USA, http://www.nitrc.org/projects/ $\mathrm{spm} /$ ). The cerebral regions of interest (cortex, hippocampus, ventricles, etc.) were then delineated by superimposing the anatomical information from a brain atlas [26] on the MR image or map. The internal anatomical mark provided by the dorsal third ventricle (Bregma $-1.46 \mathrm{~mm}$, interaural $2.34 \mathrm{~mm}$ ), was used as a common reference between the image collection and the atlas, to obtain an adequate anatomical localization of the MR sections observed in every animal. ROIs were selected with the Image J software. In vivo ${ }^{1} \mathrm{H}$ MR spectroscopy used a point-resolved spatially spectroscopy sequence (PRESS), combined with VAPOR water suppression with the following parameters: $\mathrm{TR}=3000 \mathrm{~ms}, \mathrm{TE}=35 \mathrm{~ms}, \mathrm{Av}=128$, voxel volume $=3 \mathrm{~mm}^{3}$. Clinically detectable metabolites as $\mathrm{N}$-acetylaspartic acid (NAA), total $\mathrm{Cr}$, and total Cho, were quantified by measuring the area of the peaks using the LC Model software [27]. These were in all cases below the $20 \%$ Cramér-Rao lower bound (CRLBs), an estimate of the standard deviation (SD) of the fit for each metabolite. Additional metabolites investigated by LCModel as lactate, glutamate, glutamine, myo-inositol, and taurine did not overcome the CRLBs constraints and were not further considered in the analysis.

\section{Immunohistochemical methods}

5-Bromodeoxyuridine (BrdU) (Sigma, St Louis, $\mathrm{MO}$ ), dissolved in $0.9 \% \mathrm{NaCl}$ at dose of $50 \mathrm{mg} / \mathrm{kg}$, was administered intraperitoneally (i.p.) for seven consecutive days, and the mice then sacrificed one day after the last injection. Animals were perfused 
transcardially with saline buffer or $4 \%$ paraformaldehyde in $0.1 \mathrm{M}$ phosphate buffer (PB), $\mathrm{pH}$ 7.4. Fixed brains were cut on a vibratome (Leica Microsystems) at $50 \mu \mathrm{m}$, and tissue sections were collected in cold PB 0.1 M. DNA was denatured by incubating tissue sections for $30 \mathrm{~min}$ in $2 \mathrm{~N} \mathrm{HCl}$ at room temperature. Then, sections were blocked by incubating for $15 \mathrm{~min}$ in a solution containing $10 \%$ methanol and $3 \%$ hydrogen peroxide, and incubated overnight with a mouse monoclonal anti-BrdU antibody ( $1: 20000$, DS Hybridoma Bank). For stereological estimation of $\mathrm{BrdU}^{+}$cells, all sections were processed for single BrdU immunohistochemistry using the avidin-biotin complex method (VECTASTAIN Elite ABC Kit, Vector Laboratories, Burlingame, CA). The reaction was visualized using 3,3'-diaminobenzidine (Vector Laboratories) as the chromogen. The brain was sectioned at $50 \mu \mathrm{m}$, and every sixth section, spaced $300 \mu \mathrm{m}$ apart throughout the entire rostral/caudal extent of the hippocampus (from Bregma $-1.06 \mathrm{~mm}$ to Bregma $-3.80 \mathrm{~mm}$ ), was used to assess the number of BrdU-labeled cells. In addition, brain sections were also incubated with a goat polyclonal doublecortin antibody (DCX; $1: 250$, Santa Cruz Biotechnology, Inc.) to identify neuronal progenitor cells, and with a rabbit polyclonal antiKi-67 antibody (1:500, Abcam, Cambridge, UK), a useful marker for cellular proliferation. Secondary antibodies were: donkey anti-goat IgG 488 (1:1000, FluoProbes ${ }^{\circledR}$, Interchim), and Texas Red goat antirabbit IgG antibody (Jackson Immunoresearch). These sections were co-labeled with DAPI nuclear staining (Sigma-Aldrich). The same areas and number of sections were studied in all animals and experimental groups. The specificity of the staining was tested by omitting primary antibodies from the incubation solution. Images were captured using a Zeiss LSM 510 Meta scanning laser confocal microscope (Carl Zeiss Microimaging, $\mathrm{GmbH}$ ).

\section{Statistics}

Statistical analysis was performed using the SPSS package (Version 18.0) for Windows. Levene's test was run to analyze the homogeneity of variance between wild-type mice and transgenic A $\beta P P / P S 1$ mice. All statistical tests were two-tailed $t$-test with significance set at the 0.05 level. Logistic regression analyses were performed with the MRS data in cortical and subcortical areas and with the MRI measurements in the whole brain, cortex and hippocampus [28]. To identify the independent predictors of transgenesis, the measurement from each region with the highest score and significant difference was selected and combined with other variables in a stepwise analysis. The posterior probability was calculated with the formula: $\mathrm{P}(\mathrm{x})=1 / 1+\mathrm{e}^{-\left(\beta_{\mathrm{o}}+\beta_{1} \mathrm{x}_{1}+\beta_{2} \mathrm{x}_{2}+. . \beta_{\mathrm{t}} \mathrm{x}_{\mathrm{t}}\right)}$, where $\mathrm{x}_{1}, \mathrm{x}_{2} \ldots \mathrm{x}_{\mathrm{t}}$ represent independent variables. The probability of reference for classification was 0.5 .

\section{RESULTS}

Figure 1A illustrates the anatomical location of the sixteen consecutive slices acquired by MRI increasing from the caudal to the rostral planes, respectively. Briefly, we used the dorsal third ventricle as an internal anatomical marker from control and A $\beta P P / P S 1$ mice to align, register, and compare the collection of images from each mouse. The same internal anatomical coordinates allowed the selection of the corresponding sections of the atlas that best described those obtained by MRI. Normally, the dorsal third ventricle was contained in slice 8 , providing a robust anatomical coordinate for the localization of the remaining slices. Table 1 summarizes the main anatomical regions contained in each one of the sixteen slices. In this way, the entire collection of MRI images and anatomical maps could be aligned, regionalized, and analyzed. The right insert shows a representative example of the anatomical regionalization of slice 4 , as obtained by superimposing the corresponding region from the anatomical atlas over the MRI image. We have considered three main regions in each slice: (i) the whole brain section, including all the anatomical structures therein (Table 1); (ii) the cerebral cortex; and (iii) the hippocampus, as regionalized in the MRI image by superimposing the atlas. Figure 1B depicts consecutive $\mathrm{T}_{2}$-weighted MR sections (slices 4-10) through the brain of control (upper panels) and A $\beta P P / P S 1$ mice (lower panels). The bar graphs shown below quantitatively compare the average intensity ( \pm standard error) of the three selected regions in each slice from control (white bars) and A $\beta$ PP/PS1 (black bars). The average $\mathrm{T}_{2}$-w intensity is similar in all slices of the whole brain, presenting a tendency to be higher in the A $\beta P P / P S 1$ mice in the cortex and hippocampus, with statistically significant values $(p<0.05)$ in the cortex from slices 9 and 10, primarily involved in the control of motor activities.

Figure 2 provides a quantitative comparison of the areas occupied by the ventricles (solid perimeter), and the hippocampus (broken perimeter) in different slices of control (white bars) and A $\beta P P / P S 1$ mice (black bars), as determined in the same $\mathrm{T}_{2}$-weighted image 

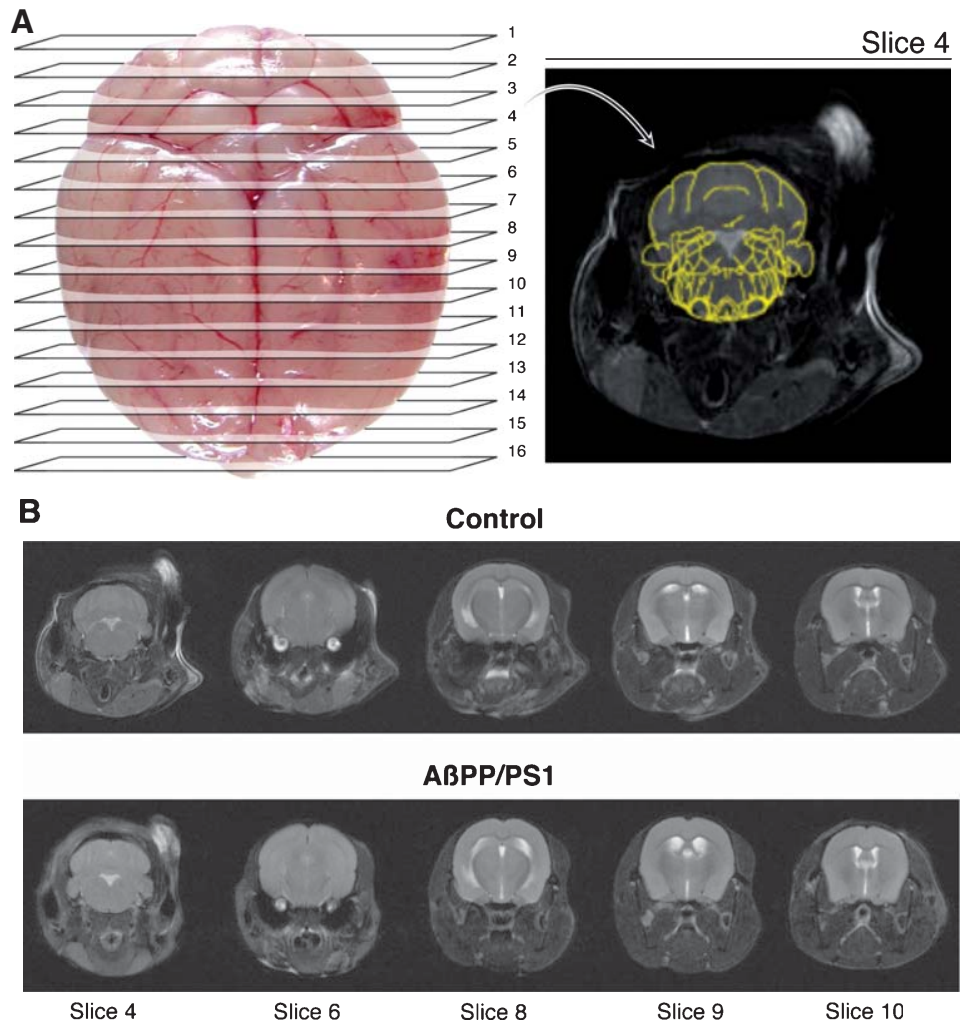

C

Whole Brain
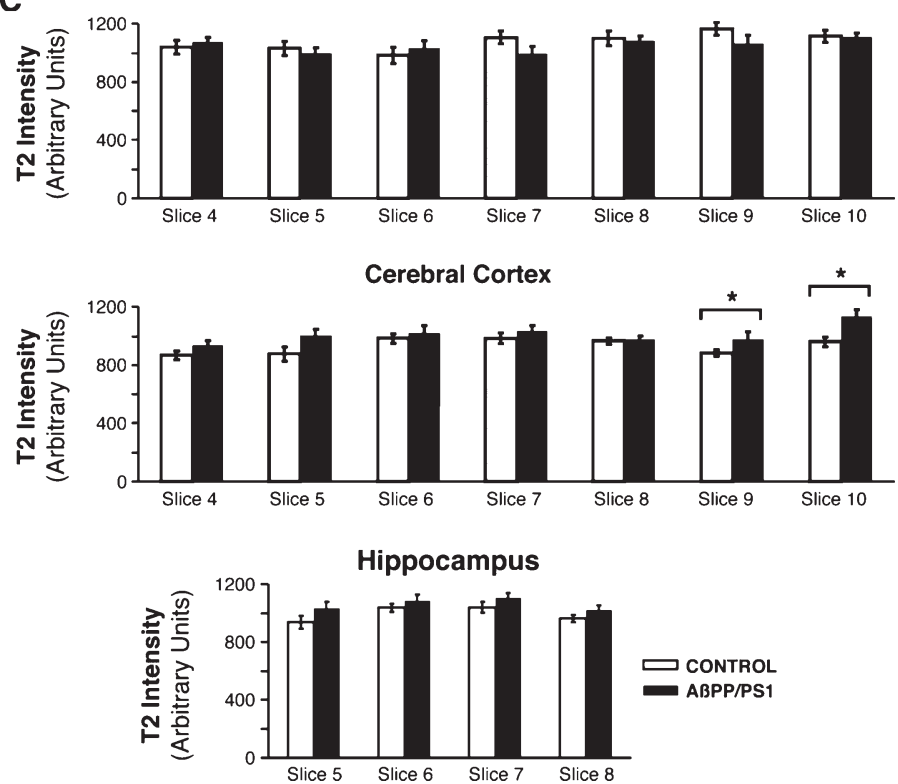

Fig. 1. In vivo $\mathrm{T}_{2}$-weighted brain images of wild-type and A $\beta P P / P S 1$ mice. A) Sixteen consecutive slices (1 mm thick), with increasing numbering in the caudal to rostral direction were acquired for each mouse (left panel). Regionalization was performed using the dorsal third ventricle as a common anatomical reference between the cerebral image and the Paxinus atlas (right panel). $\mathrm{B}$ ) $\mathrm{T}_{2}$-weighted images (slices 4-10) through the coronal plane of control and A $\beta P P / P S 1$ mice. C) Relative intensity in the whole brain, cerebral cortex and hippocampus as determined in each slice using the ImageJ software. Values shown are the mean \pm standard error (control mice $n=8 ; \mathrm{Tg}$ mice $n=7)$. ${ }^{*} p<0.05$. 
Table 1

Main anatomical structures found in each $\mathrm{T}_{2}$ slice, as determined in the anatomical atlas. Percent values indicated for the corresponding anatomical structures indicate the relative area of the structure(s) as compared to that of the complete cerebral section, as described in [26]

\begin{tabular}{|c|c|}
\hline Slice & Main anatomical structures \\
\hline \multirow[t]{2}{*}{ Slice 2} & Cerebellum $65 \%$ \\
\hline & Hindbrain $35 \%$ \\
\hline \multirow[t]{3}{*}{ Slice 3} & Cerebellum $60 \%$ \\
\hline & Hindbrain $38 \%$ \\
\hline & Ventricles - Fourth ventricle $2 \%$ \\
\hline \multirow[t]{3}{*}{ Slice 4} & Cerebellum $60 \%$ \\
\hline & Hindbrain (Medulla and pons) $33 \%$ \\
\hline & Ventricles - Fourth ventricle $7 \%$ \\
\hline \multirow[t]{3}{*}{ Slice 5} & Cerebral cortex $55 \%$ \\
\hline & Midbrain $25 \%$ \\
\hline & Hindbrain (Pons and medulla) $20 \%$ \\
\hline \multirow[t]{4}{*}{ Slice 6} & Midbrain $37 \%$ \\
\hline & Cerebral cortex $35 \%$ \\
\hline & Hippocampus $25 \%$ \\
\hline & Thalamus $3 \%$ \\
\hline \multirow[t]{6}{*}{ Slice 7} & Cerebral cortex $40 \%$ \\
\hline & Hippocampus $15 \%$ \\
\hline & Ventricles $15 \%$ \\
\hline & Hypothalamus $12 \%$ \\
\hline & Thalamus $12 \%$ \\
\hline & Midbrain $6 \%$ \\
\hline \multirow[t]{6}{*}{ Slice 8} & Cerebral cortex $54 \%$ \\
\hline & Thalamus $20 \%$ \\
\hline & Cerebral nuclei (Striatum, Pallidum) $8 \%$ \\
\hline & Hypothalamus $8 \%$ \\
\hline & Ventricles $6 \%$ \\
\hline & Hippocampus $4 \%$ \\
\hline \multirow[t]{6}{*}{ Slice 9} & Cerebral cortex $45 \%$ \\
\hline & Cerebral nuclei (Striatum, Pallidum) $25 \%$ \\
\hline & Ventricles $10 \%$ \\
\hline & Thalamus $9 \%$ \\
\hline & Hypothalamus $9 \%$ \\
\hline & Hippocampus $2 \%$ \\
\hline \multirow[t]{5}{*}{ Slice 10} & Cerebral cortex $45 \%$ \\
\hline & Cerebral nuclei (Striatum, Pallidum) 35\% \\
\hline & Ventricles $10 \%$ \\
\hline & Hypothalamus $5 \%$ \\
\hline & Thalamus 5\% \\
\hline \multirow[t]{4}{*}{ Slice 11} & Cerebral cortex $54 \%$ \\
\hline & Nuclei $40 \%$ \\
\hline & Hypothalamus $3 \%$ \\
\hline & Ventricles $3 \%$ \\
\hline \multirow[t]{2}{*}{ Slice 12} & Cerebral cortex $70 \%$ \\
\hline & Cerebral nuclei $30 \%$ \\
\hline Slice 13 & Cerebral cortex $100 \%$ \\
\hline
\end{tabular}

data set shown in Fig. 1. The relative ventricular area is significantly larger $(* p<0.05)$ in slices $8-10$, while the relative hippocampal area decreases significantly $\left({ }^{*} p<0.05\right)$ in slice 9 of the A $\beta P P / P S 1$ mice (Fig. 2B, C). A more detailed analysis of the areas corresponding to the left and right lateral ventricles, the third ventricle, and the third dorsal ventricle showed that the differences are found mainly between the areas of the left and right lateral ventricles (Fig. 2D). When we calculate the corresponding ventricular and hippocampal relative volumes (Fig. 2E, F) by multiplying the measured areas by the thickness of the MRI sections, the ventricular volumes are appreciably larger while the hippocampal volumes remained smaller in the A $\beta P P / P S 1$ mice.

To investigate the possibilities that these increases in ventricular volume of A $\beta P P / P S 1$ mice would involve edema of the cerebral parenchyma, we have studied the effects of the A $\beta P P / P S 1$ genotype on the MT and ADC Maps. In these cases, we acquired only five slices through brain; slice 4 in these acquisitions corresponds essentially to slice 9 of the former series, maintaining the same coordinate system. The main anatomical structures included in these slices are summarized in Table 2. Fig. 3 compares MT maps, obtained as indicated in the Methods, from the whole brain, cerebral cortex, and hippocampus from representative slices (1-5) of control and A $\beta P P / P S 1$ mice. The A $\beta P P / P S 1$ genotype results in a decrease of relative MT in all structures investigated. The decrease becomes statistically significant $(* p<0.05)$ in whole brain (slices 3 and 5), cerebral cortex (slices 3-5), and hippocampus (slice 3).

To confirm this hypothesis, we obtained ADC maps from the same slices (1-5) of control and A $\beta P P / P S 1$ mice (Fig. 4). ADC maps show a tendency to increase in the three regions, with more apparent increases in slices 2 and 4 of the whole brain and cerebral cortex and slice 2 of the hippocampus. These results reveal a relative increase of the ADC consistent with an increased ventricular volume and intracellular water content or decreased averaged obstructions to water translation. Together, the MT and ADC maps obtained are consistent with a generalized cerebral edema in the brain from A $\beta P P / P S 1$ mice.

We further investigated the effects of the A $\beta P P / P S 1$ genotype on the ${ }^{1} \mathrm{H}$ MRS spectra obtained from the cortex (Fig. 5A, B) and subcortical areas (Fig. 5D, E). Figure 5 shows representative results from ${ }^{1} \mathrm{H}$ MRS spectra obtained from these regions from control (Fig. 5A, D) and A $\beta P P / P S 1$ mice (Fig. 5B, E). A quantitative analysis of the relative intensities of the NAA, total Cr, and total Cho resonances, the metabolites most commonly detected in clinical scanners, is shown in the bar graphs of Fig. 5C, F. While the $\mathrm{NAA} / \mathrm{Cr}$ does not change appreciably between control and $\mathrm{A} \beta P P / P S 1$ mice, the $\mathrm{Cho} / \mathrm{Cr}$ ratio increases significantly $\left({ }^{*} p<0.005\right)$ in the cortical and subcortical areas of the A $\beta P P / P S 1$ mice. It should be noted here that the Cho peak is a composite resonance containing unresolvable contributions in vivo from choline, 
A

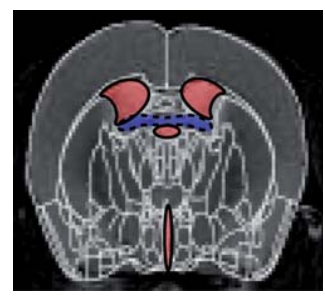

B

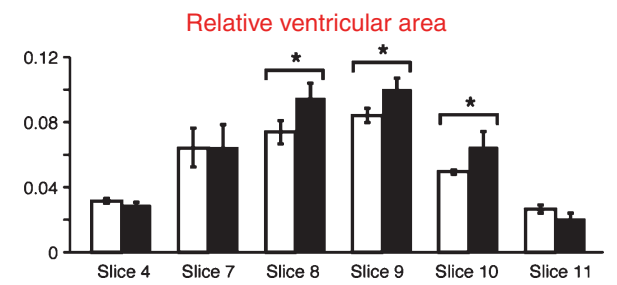

E
C

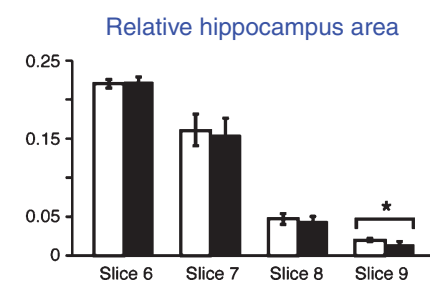

D Slice 9

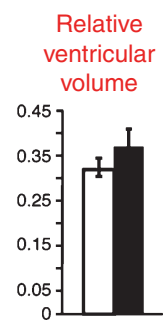

$\mathbf{F}$

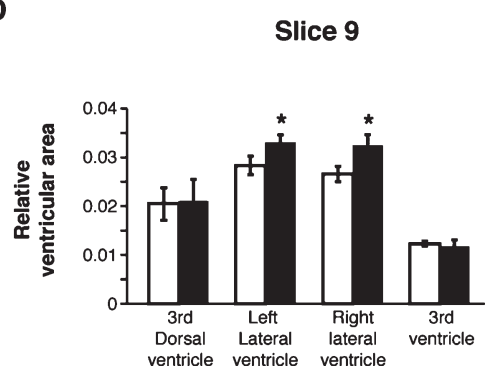

ventricle ventricle ventricle

Fig. 2. Comparison between ventricular and hippocampus size in wild-type and A PPP/PS1 mice. A) Regions used to determine the ventricular area (solid line) and hippocampus area (broken line). B, C) Ventricular and hippocampus areas are expressed relatively to the total brain area of each slice in control (white bars) and AßPP/PS1 (black bars) mice. Values are the mean \pm standard error (control mice $n=8 ; \mathrm{Tg}$ mice $n=7$ ). ${ }^{*} p<0.05$. D) Ventricular enlargement occurs primarily in the lateral ventricles. E, F) Ventricular or hippocampus volumes were determined from the addition of the relative volumes of these structures in the corresponding slices, calculated as the product of their relative area by slice thickness.

Table 2

Main anatomical structures observed in each MT and ADC slice, as determined in the anatomical atlas. Percent values indicated for the corresponding anatomical structures indicate the relative area of the structure as compared to that of the complete cerebral section, as described in [26]

\begin{tabular}{ll}
\hline Slice & Main anatomical structures \\
\hline Slice 1 & Midbrain 37\% \\
(Slice 6 in $\left.\mathrm{T}_{2}\right)$ & Cerebral cortex 35\% \\
& Hippocampus 25\% \\
& Thalamus 3\% \\
Slice 2 & Cerebral cortex 40\% \\
(Slice 7 in $\left.\mathrm{T}_{2}\right)$ & Hippocampus 15\% \\
& Ventricles 15\% \\
& Hypothalamus 12\% \\
& Thalamus 12\% \\
& Midbrain 6\% \\
Slice 3 & Cerebral cortex 45\% \\
$\left(\right.$ Slice 9 in $\left.\mathrm{T}_{2}\right)$ & Cerebral nuclei (Striatum, Pallidum) 25\% \\
& Ventricles 10\% \\
& Thalamus 9\% \\
& Hypothalamus 9\% \\
& Hippocampus 2\% \\
Slice 4 & Cerebral cortex 45\% \\
$\left(\right.$ Slice 10 in $\left.\mathrm{T}_{2}\right)$ & Cerebral nuclei (Striatum, Pallidum) 35\% \\
& Ventricles 10\% \\
& Hypothalamus 5\% \\
& Thalamus 5\% \\
Slice 5 & Cerebral cortex 54\% \\
(Slice 11 in $\left.\mathrm{T}_{2}\right)$ & Nuclei 40\% \\
& Hypothalamus 3\% \\
& Ventricles 3\% \\
\hline
\end{tabular}

phosphorylcholine, and glycerolphosphorylcholine. Under these circumstances the increases observed could be due to augmented concentrations of one or more of these metabolites.

\section{Proliferation of neuronal progenitors is enhanced in $A \beta P P / P S 1$ mice}

High MRS Cho signals are accepted predictors of accelerated membranous turnover and proliferative activity. Although glial proliferation may be expected in the transgenic mice, as it was reported in AD brain [29], we found it interesting to elucidate whether neurogenesis could be perturbed in the A $\beta P P / P S 1$ mice. For these experiments, mice were injected with BrdU for seven days prior the determination of BrdU incorporation by immunohistochemistry. Figure 6 shows that the number of $\mathrm{BrdU}^{+}$cells in the hippocampus, including dentate gyrus (DG), CA1, and CA3 is significantly higher $(* p<0.05)$ in the transgenic mice than in the wild-type littermate mice. Proliferation of neuronal progenitors in the hippocampus of control and AßPP/PS1 mice was also labeled by Ki-67 and DCX staining. Representative photomicrographs of Ki-67 and DCX staining are shown in Fig. 7A, B, respectively. 


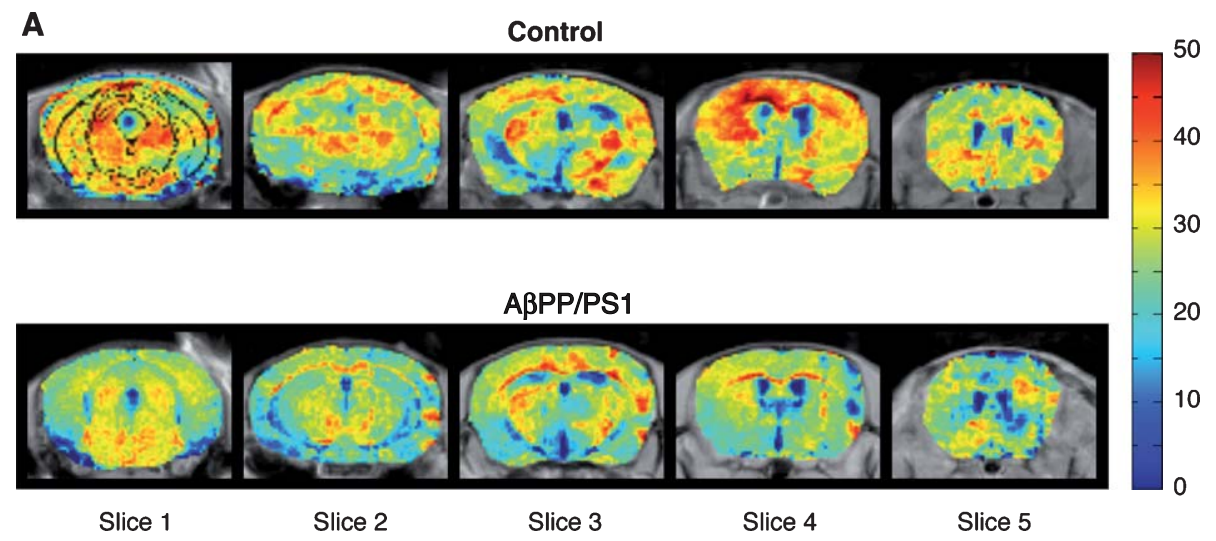

B
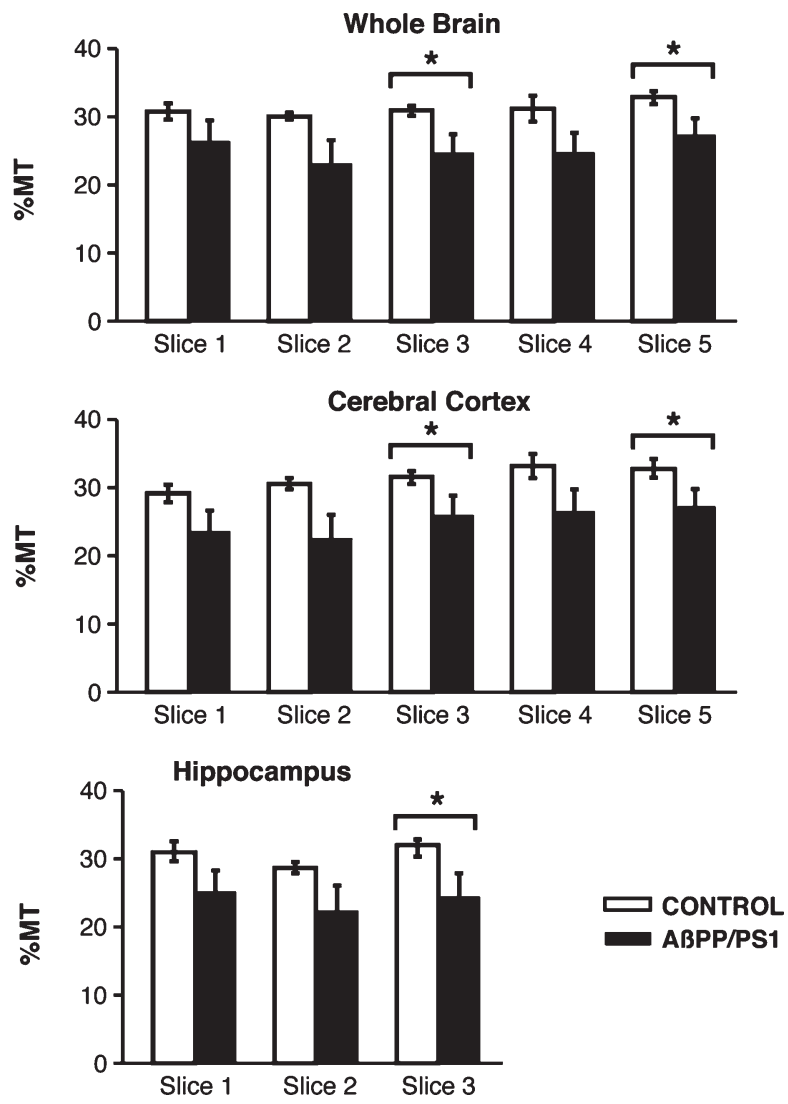

Fig. 3. Comparison between MT Maps from wild-type and AßPP/PS1 mice. A) \% MT maps in slices 1-5 of control (top) and A $3 P P / P S 1$ mice. Note the decrease in \% MT in A $\beta$ PP/PS1. B) Regional \% MT maps in whole brain (top), cerebral cortex (center) and hippocampus (bottom) of control (white bars) and A $\beta$ PP/PS1 (black bars) mice. Values shown represent the mean \pm standard error (control mice $n=8$; Tg mice $n=7$ ). $* p<0.05$.

\section{Logistic regression analyses of MR parameters}

Logistic regression analyses were performed for MRI data in whole brain, cerebral cortex, and hippocampus, as well as for the MRS data in the cortical and subcortical areas, to identify within these different biomarkers those that best discriminate between the control and A $\beta$ PP/PS1 groups. For each region, the measurement with the highest score and significant difference was selected and combined sequentially and hierarchically with the remaining variables as indicated in the legend (Fig. 8). 

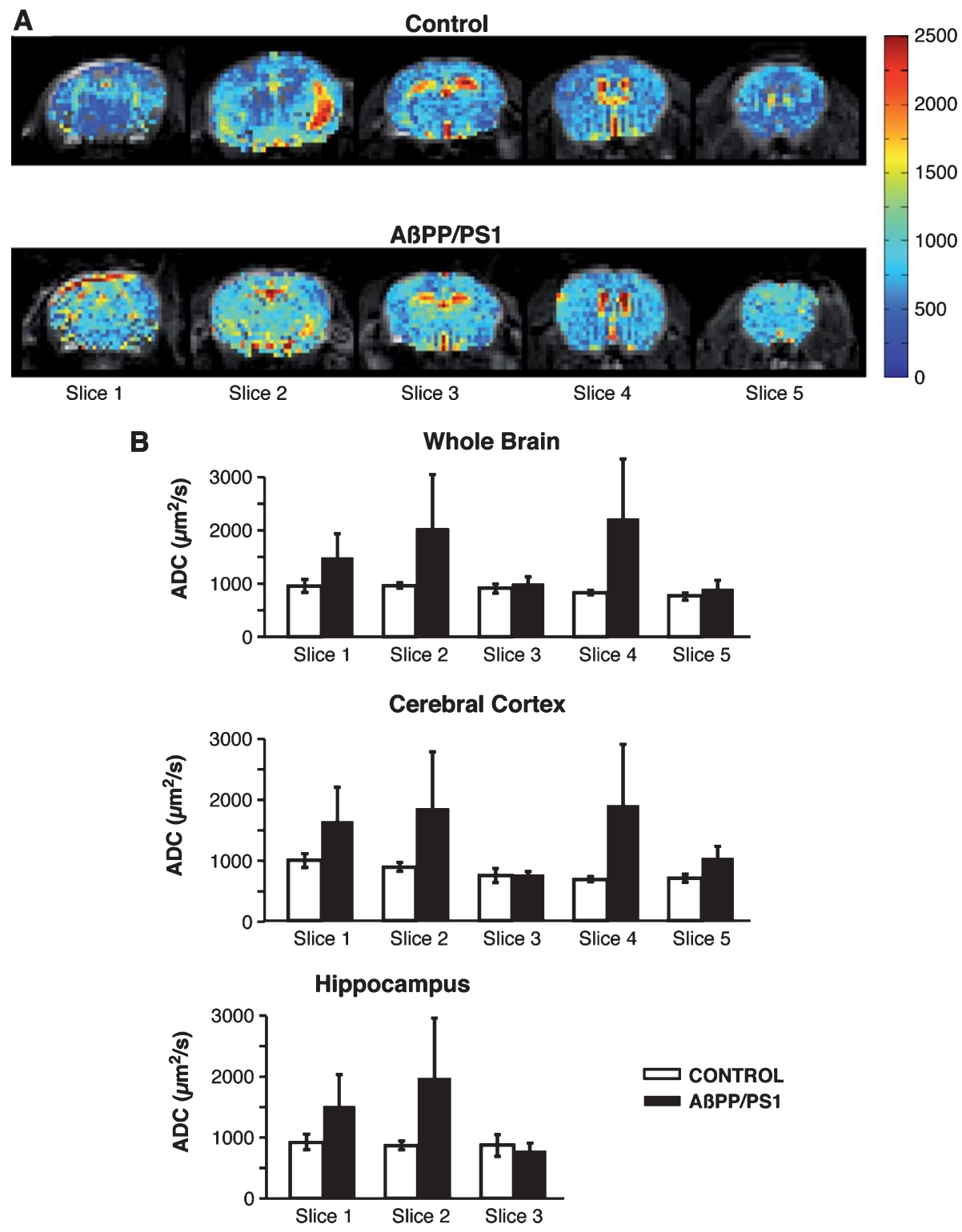

Fig. 4. Comparison between ADC maps from wild-type and A $\beta P P / P S 1$ mice. A) ADC maps in slices 1-5 of Control (top) and A $3 P P / P S 1$ mice. Note the average increase in the color scale ADC in A $3 P$ P/PS1. B) Regional ADC maps in whole brain (top), cerebral cortex (center) and hippocampus (bottom) of control (white bars) and A $\beta$ PP/PS1 (black bars) mice. Values shown represent the mean \pm standard error (control mice $n=8$; Tg mice $n=7$ ).

Figure 8A summarizes the individual posterior probability of being correctly classified as control (open symbols) or transgenic mice (filled symbols), while Fig. 8B depicts the percentages of sensitivity/specificity of the classifier, found by using different combinations of MRI or MRS parameters. These values are 86/87 when combining $\mathrm{T}_{2}$ signal in slice 9 and 4 in the whole brain (see Table 1 for main anatomical regions involved). The same values were obtained in the cerebral cortex with the $\mathrm{T}_{2}$ signal in slice 10 plus the $\%$ of MT in slice 2 , and reached the $100 \%$ classification success when the ADC value in slice 1 is included. MRI parameters in the hippocampus had no statistically significant discriminatory value. Interestingly, the ventricular or the hippocampal areas provided relatively poor accuracy in distinguishing A $\beta P P / P S 1$ from control mice ( $72 \%$ and $66 \%$ respectively). Analysis of the MRS data indicates that the ratio of $\mathrm{Cho} / \mathrm{Cr}$ 

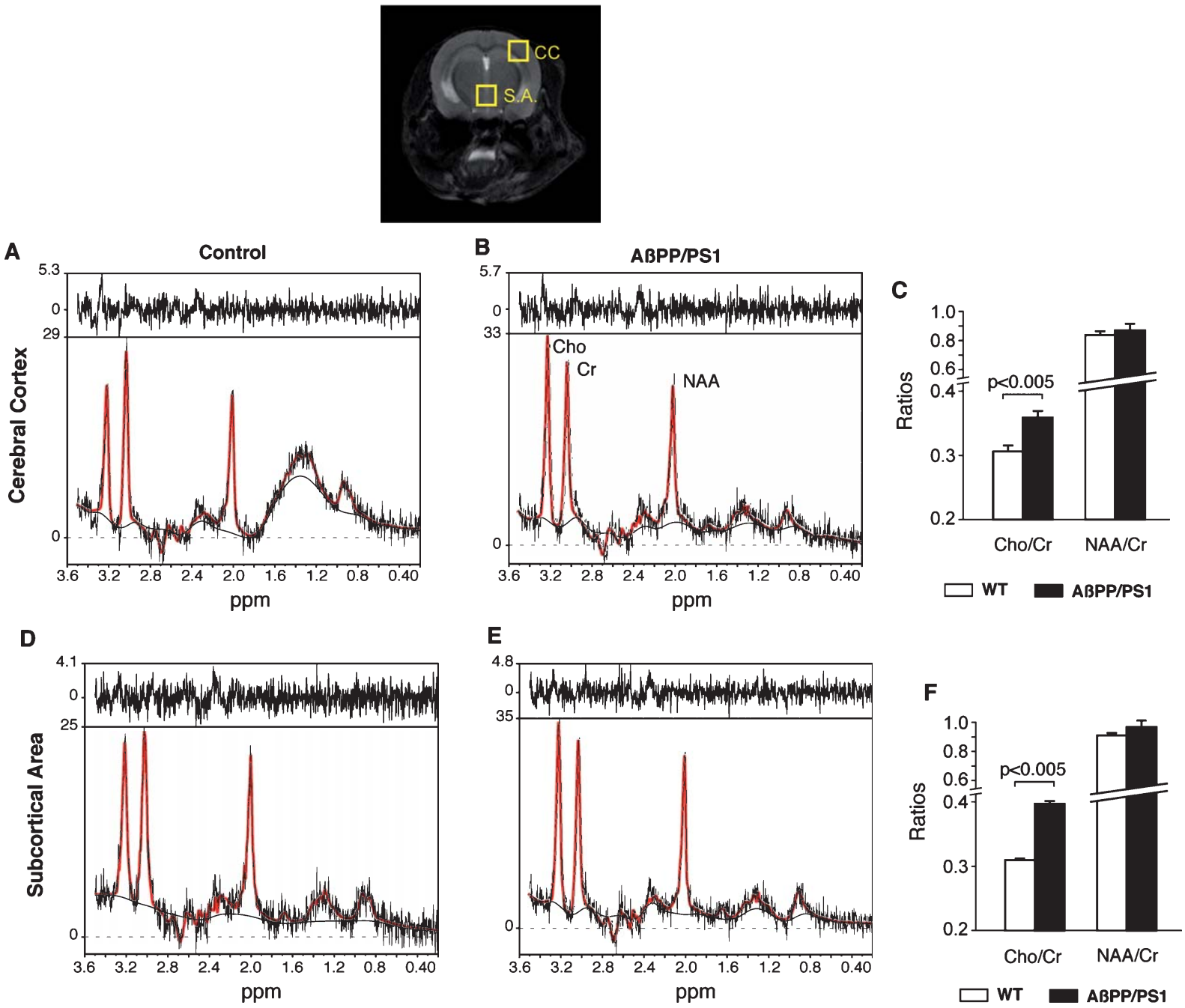

Fig. 5. In vivo ${ }^{1} \mathrm{H}$ PRESS spectra from cortical and subcortical areas of wild-type and A $\beta P P / P S 1$ mice. Top insert: Cortical and subcortical voxel localization (yellow squares). Representative spectra form cortical (A,B) and subcortical (D,E) areas of control and A $\beta P P / P S 1$ mice, respectively. $\mathrm{Cho} / \mathrm{Cr}$ and NAA/Cr ratios in the cortical (C) and subcortical (F) regions of control (white bars) and AßPP/PS1 (black bars) mice. Note the significant increase in $\mathrm{Cho} / \mathrm{Cr}$ ratio in the AßPP/PS1 mice. Values shown are the mean \pm standard error (control mice $n=8 ; \mathrm{Tg}$ mice $n=7)$.

in the subcortical area is the best predictor, since it completely and precisely discriminates between control and transgenic mice, just in the first step. It is worthwhile mentioning here that the same ratio $\mathrm{Cho} / \mathrm{Cr}$ in the cortex provides lower scores, highlighting the importance of the region selection procedure in the diagnostic process.

\section{DISCUSSION}

The search for homologous biomarkers of disease for humans and animals represents an important step in the drug discovery process. When found, these may be applied longitudinally both during preclinical research and in the clinical trials, in a fully translational environment during therapy evaluation. AD biomarkers are biochemical and anatomical variables that measure AD-related pathological features. Biomarkers are either utilized for early diagnosis in asymptomatic individuals or as end-point biomarkers in symptomatic subjects or in disease-modifying therapies. Non-invasive biomarkers, such as those provided by MRI and MRS are endowed with optimal properties for these purposes, mainly because their non-invasive character and the applications of the same MRI/MRS 
A
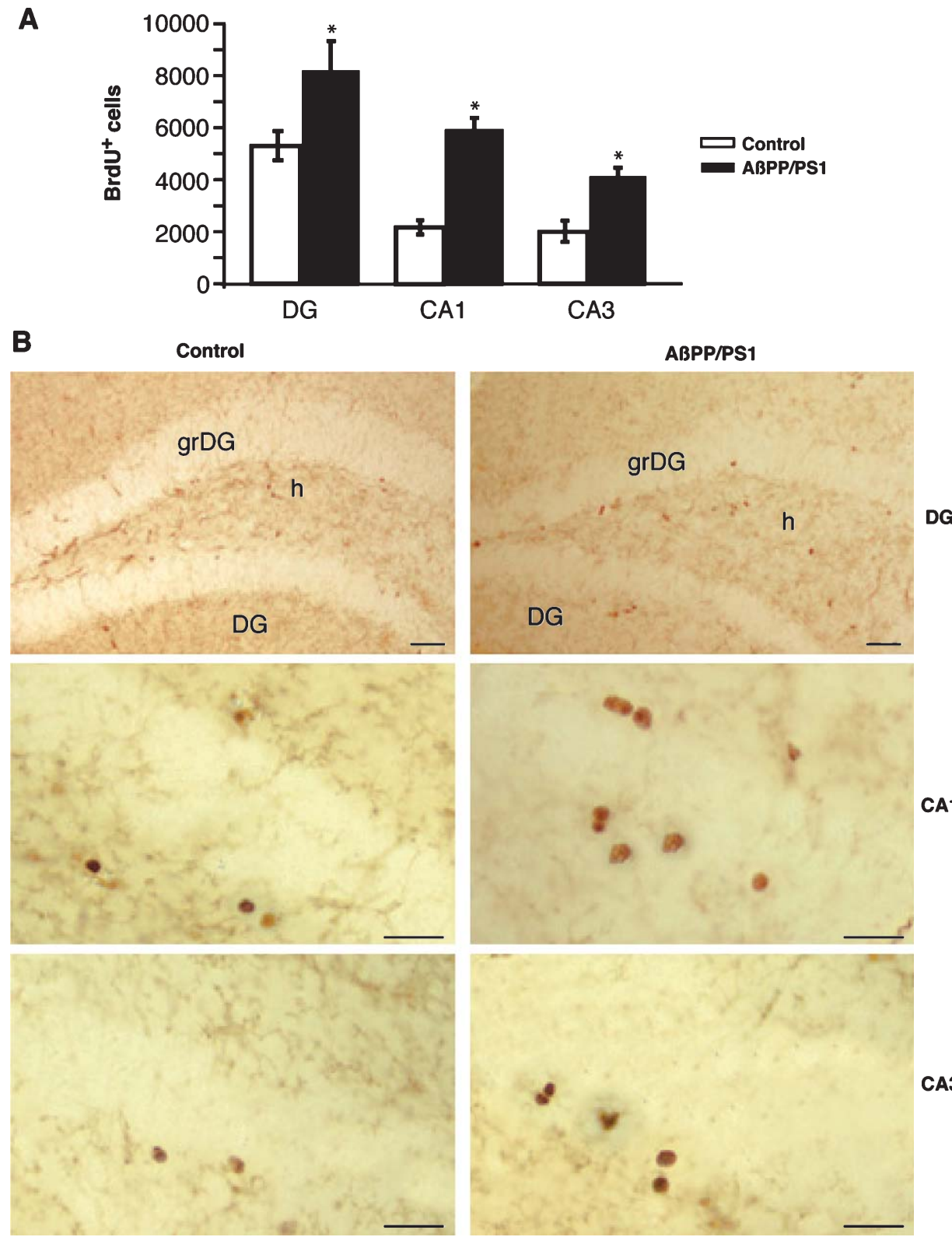

Fig. 6. Cell proliferation labelling by BrdU staining in the hippocampus of wild-type and A $\beta P P / P S 1$ mice. A) Histograms show the number of $\mathrm{BrdU}^{+}$nuclei in control (white bars) and A $3 P P / P S 1$ (black bars). Data are expressed as mean \pm standard error. * $p<0.05$; (control mice $n=8$; Tg mice $n=7$ ). B) Photomicrographs, with different magnification, show BrdU ${ }^{+}$nuclei in the dentate gyrus (DG), CA1, and CA3 of control and A $\beta P P / P S 1$. Scale bars $=20 \mu \mathrm{m}$. grDG: Granular layer of the dentate gyrus; h: hippocampus.

methods both to animals and humans [12,30,31]. Previous studies in mouse models of $\mathrm{AD}$ have mainly focused on the A $\beta$ burden [32-34], volumetric changes $[18,35]$, or even MRS parameters, as predominant markers for $\mathrm{AD}[36,37]$. Here, we have implemented a different approach. We have applied a series of
MRI/MRS methods to investigate the complete mouse brain and obtain a comprehensive database containing the most commonly used MRI/MRS biomarkers including $\mathrm{T}_{2}$, MT, and ADC as well as regionalized cortical and subcortical MRS. We have then used a logistic regression algorithm to choose within all these, the 
A

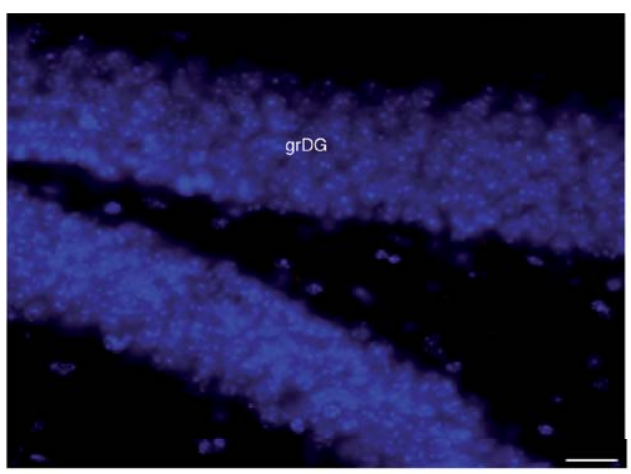

ABPP/PS1

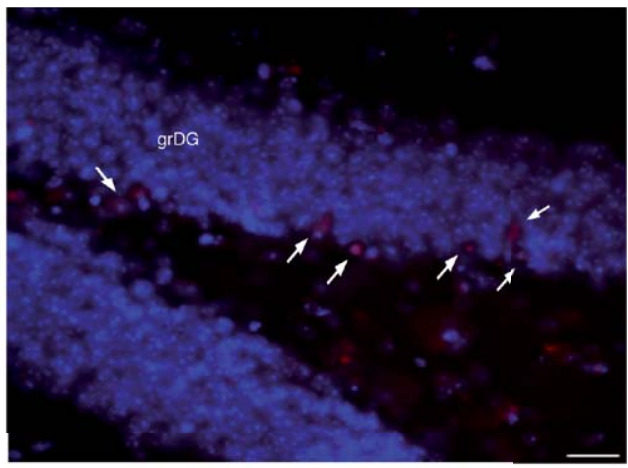

DAPI/Ki-67
Control

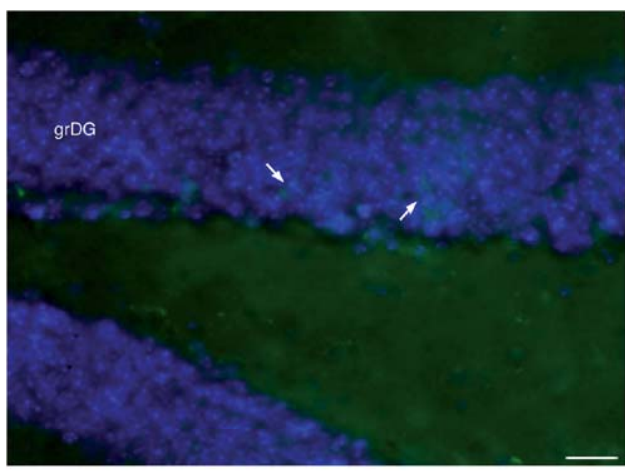

ABPP/PS1

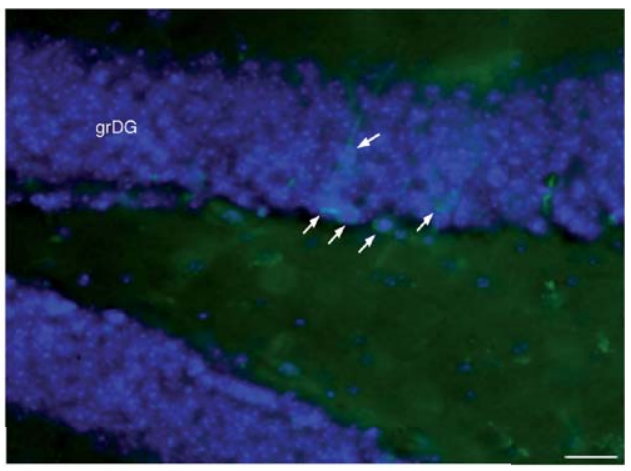

DAPI/DCX

Fig. 7. Representative photomicrographs of Ki-67 and DCX in the DG of wild-type and A $\beta P P / P S 1$ mice. Photomicrographs show (A) fluorescent Ki-67 (red) and (B) DCX (green) staining in the granule cell layer of the dentate gyrus in A $\beta P P / P S 1$ mice. Nuclei were counterstained with DAPI (blue). Scale bars $=20 \mu \mathrm{m}$. grDG: Granular layer of the dentate gyrus.

biomarker or combination of biomarkers that provided the best discrimination between normal and double transgenic A $\beta P P / P S 1$ mice.

In humans, diagnostic MRI examinations are normally targeted to the detection of medial temporal lobe (MTL) atrophy, as well as inflammatory glial infiltrations and neuronal degeneration. Inflammatory responses occur with an increase in cerebral water content normally resulting in astrocytic swelling. These effects may be visualized as increased $\mathrm{T}_{2}$ and ADC values and decreased MT values in the corresponding images. We detect increased $\mathrm{T}_{2}$ intensity values in the hippocampus and cortex of the A $\beta P P / P S 1$ mice compatible with the signs of neuroinflammation and neurodegeneration previously described in this model of AD [23].

Ventricular enlargement is a MRI-based structural biomarker typically characterizing $\operatorname{AD}[30,38]$.
Hemispheric atrophy rates, as measured by ventricular enlargement, correlate more strongly with changes on cognitive tests than MTL atrophy rates [39]. Moreover, ventricular enlargement and/or brain atrophy correlate well with declining performance in cognitive scales [40] and the rate of ventricular volume changes is highly correlated with an increase in $A \beta-$ bearing plaques and NFTs [41]. In this study, we describe a significant ventricular enlargement in the A $\beta P P / P S 1$ mice with the lateral ventricles being the most affected. Interestingly, ventricular engorgement has also been reported in a tau mouse model of AD [42]. It has been reported, however, that the pattern of lifetime ventricular expansion in mice differs from that found on humans, thus the physiological ventricular enlargement during normal aging must be taken into account in related experiments [43]. In our study, ventricular enlargement is accompanied by a discrete 
A
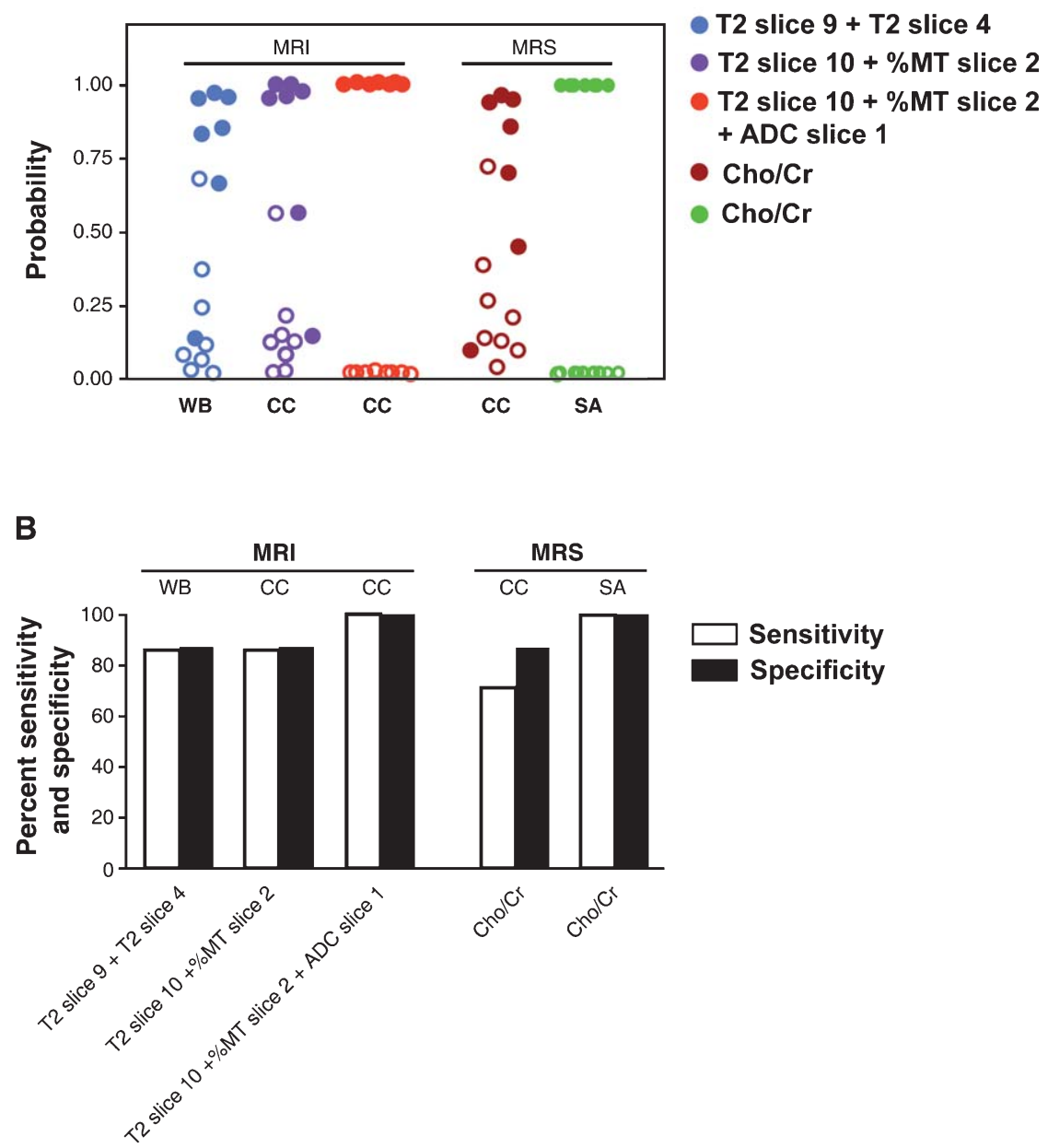

Fig. 8. Discriminatory potential of MRI and MRS parameters using logistic regression analysis. A) Scatter plots showing the individual posterior probability for being correctly classified as 0: wild-type mice or 1: A $\beta P P / P S 1$ mice using different MRI and MRS combination of variables. The first parameter of each region corresponds with the one with the highest score, followed hierarchically by the next variables. Open symbols: control mice; filled symbols: transgenic animals. B) Sensitivity (white bars) and specificity (black bars) of control and A $\beta P P / P S 1$ mice by using logistic regression analyses. WB: whole brain; CC: cerebral cortex; SA: subcortical area.

hippocampal volume decrease in the A $\beta P P / P S 1$ mice. There are conflicting results in the literature regarding hippocampal changes in different mouse models of AD. While some authors reported decreased hippocampal volume in the PDA $\beta$ PP or the A $\beta P P / P S 1$ mice [44, 45], others reported enlarged hippocampus in the TASTPM mice [46]. Thus, genetic background or transgene expression, as well as other factors such as the age of animals or even the method of measurement, may play a role in the differences found. Taken together, it seems that ventricular enlargement, rather than hippocampal volume in transgenic mouse models of AD may have a better clinical translational potential for AD diagnosis.
MT imaging can provide pathophysiological information about the microstructure of the brain, reflecting the underlying histopathology changes. As previously reported for patients with AD [47-49], we detect a significant decrease in \% MT in the cortex and hippocampus, as well as in the whole brain of the A $\beta P P / P S 1$ mice. Localized alterations in the \% MT have been associated with cognitive status in MCI and $\mathrm{AD}$ patients $[50,51]$. The mechanisms underlying \% MT reduction in the brain of AD patients are not completely understood, but they could involve changes in the relative ratio between free and macromolecule bound water molecules and their exchange occurring during inflammation. Additionally, it has been 
suggested that decreased \% MT could reflect changes associated with neuronal loss, accumulation of plaques and NFTs, and gliosis [52].

By measuring ADC values, one can quantify alterations in apparent water diffusivity resulting from changes associated with brain injury and/or disease progression [53]. A trend towards higher ADC values is observed in whole brain as well as hippocampus or cortex of the A $\beta P P / P S 1$, compared to control mice, but these trends are not statistically significant. Similar findings were reported in other AD mouse model that expresses a double mutant form of hAßPP 695 (K670 N/M671 L and V717F) [54].

In this work, we combine MRI analyses with additional MRS to unravel quantitatively metabolic and biochemical changes in the brain tissue in vivo. Reduction of NAA has been widely used as an indicator of brain pathology and of disease progression in $\mathrm{AD}$ patients [55-59]. Alterations in NAA/Cr have been also detected in the hippocampus of 6.5-9 month-old A $\beta P P / P S 1$ mice [45]. In contrast, we do not observe significant changes in the NAA/Cr ratio in the cortical or subcortical regions of the A $\beta P P / P S 1$ mice. Our results, however, are in agreement with previous reports in double transgenic mice (A $\beta P P / P S 1)$ that show decreased ratio of NAA/Cr, but only in mice $>$ twelve months-old [36]. Agedependent changes in brain NAA levels correlating with increasing amyloidosis have also been reported in the PS2A 3 PP mouse model of AD [37].

An increase in the ratio of $\mathrm{Cho} / \mathrm{Cr}$ levels has been found in the cortex and subcortical areas of A $\beta P P / P S 1$ mice compared with wild-type littermates. Changes in the concentration of Cho were not observed in previous mouse AD models [36]. This discrepancy in observed metabolites may arise from variations in the region of the brain sampled as well as from age or intrinsic differences among mouse models. In humans, there are conflicting reports about Cho levels in $\mathrm{AD}$ sufferers; whereas some authors found elevated Cho/Cr levels [60], others did not [61, 62]. Notably, wild-type and A $\beta P P / P S 1$ mice were completely differentiated at twelve months of age, when $A \beta$ deposits are widespread, by the ratio of $\mathrm{Cho} / \mathrm{Cr}$. This ratio could, therefore, provide a highly sensitive in vivo surrogate marker of disease status, at least in twelve month-old mice. Interestingly, a prospective study involving 509 elderly persons showed that persons with high $\mathrm{Cho} / \mathrm{Cr}$ ratio had a higher risk to develop dementia within four years [63]. Moreover, it has been recently reported that high $\mathrm{Cho} / \mathrm{Cr}$ ratios are associated with the preclinical pathologic processes in the AD cascade. Elevated
Cho/Cr ratios correlated with decreased performance on domain-specific cognitive tests independent of $A \beta$ load [64].

The higher Cho/Cr ratio in A $\beta P P / P S 1$ mice correlates with enhanced neurogenesis as assessed by BrdU incorporation and the co-localization of the proliferation marker Ki-67 and the neuronal precursor marker DCX. Several mouse models of AD have been found to display altered adult neurogenesis, although there are conflicting results as to whether neurogenesis is decreased or increased [65, 66]. The increased proliferation of neuronal progenitors reported here in the twelve month-old A $\beta P P / P S 1$ mice is in agreement with recent work indicating a role for leptin inducing similar cell proliferation in the hippocampus of the adult A $\beta P P / P S 1$ mice [67], and with human postmortem brain study of AD patients that showed increased hippocampal neurogenesis in DG and CA1 [68]. An increase in the proliferation of neuronal progenitors may represent the compensatory response to brain damage; however, additional work is needed to elucidate if these progenitors are able to differentiate in mature functional neurons that successfully integrate into the adult mouse brain circuitry. Another possible explanation for the increased Cho levels in $\mathrm{AD}$ and in the A $\beta P P / P S 1$ mice is that the Cho peak is the consequence of membrane phosphatidylcholine catabolism in order to provide free choline for the chronically deficient acetylcholine production in $\mathrm{AD}$ [69]. The fact that the increase of $\mathrm{Cho} / \mathrm{Cr}$ levels in striatum of $\mathrm{A} \beta \mathrm{PP} / \mathrm{PS} 1$ mice is partially mitigated by treatment with the acetylcholine-esterase inhibitor donepezil [70] raises the possibility that $\mathrm{Cho} / \mathrm{Cr}$ levels could be used as a biomarker of therapeutic efficacy in AD trials. This result is also in line with a study made in $\mathrm{AD}$ patients, showing decreased levels of $\mathrm{Cho} / \mathrm{Cr}$ after four months of donepezil treatment [71].

Logistic regression analyses indicate that the most sensitive single measurement to discriminate control from A $\beta P P / P S 1$ mice that are twelve months of age is the subcortical $\mathrm{Cho} / \mathrm{Cr}$ ratio. The combination of MRI measurements in the cerebral cortex $\left(\mathrm{T}_{2}\right.$ slice 10 plus \% MT slice 4 and ADC slice 1) also fully discriminates both groups of animals. Other measurements such as volumetric changes also provide useful information about disease status, although with lower sensitivity/specificity scores. Taken together, these observations highlight the clinical usefulness of MRS-based biomarkers.

An important limitation of the present study relies in that only twelve month-old mice were used. Therefore, the observed changes must be considered only 
as potential biomarkers for disease status, supporting diagnosis, but their ability to monitor disease progression remains to be proven by longitudinal studies.

The AD model used in the present study was previously characterized by the amyloid burden, behavioral deficit, and neuronal degeneration and synaptic loss $[20,23,24]$. Together with the MRI/MRS methods described here, it now represents a well-characterized model for preclinical imaging and pathological studies of AD. Moreover, there is good agreement between changes observed in the brain of A $\beta P P / P S 1$ mice here and those reported in humans. We believe then that the results reported herein may hopefully provide valid translational clues for $\mathrm{AD}$ evaluation as well as for the development and validation of novel therapeutic strategies.

\section{ACKNOWLEDGMENTS}

Authors are indebted to the SIERMAC (http://www.siermac.es) for providing expert NMR technical assistance. Special thanks are given to $\mathrm{Mr}$. Javier Pérez for careful drafting of the illustrations. This work has been supported by grants from Ministerio de Ciencia e Innovación (SAF2007-624505 and SAF2010-1700) and Fundación Eugenio Rodríguez Pascual to A.M.R., grants from Instituto de Salud Carlos III (PI060155), Fundación Investigación Médica Mutua Madrileña (2006.125, 2008.93), and CIBERNED to E.C., grants SAF 2008-01327 and BIO2006-170 from Ministerio de Ciencia e Innovación and the Comunidad Autónoma de Madrid to S.C. N.E. holds a fellowship of the JAE predoctoral program of the CSIC.

Authors' disclosures available online (http://www.jalz.com/disclosures/view.php?id=1171).

\section{REFERENCES}

[1] Jellinger KA (2006) Alzheimer 100-highlights in the history of Alzheimer research. J Neural Transm 113, 1603-1623.

[2] Goedert M, Spillantini MG (2006) A century of Alzheimer's disease. Science 314, 777-781.

[3] Rovelet-Lecrux A, Hannequin D, Raux G, Le Meur N, Laquerriere A, Vital A, Dumanchin C, Feuillette S, Brice A, Vercelletto M, Dubas F, Frebourg T, Campion D (2006) APP locus duplication causes autosomal dominant earlyonset Alzheimer disease with cerebral amyloid angiopathy. Nat Genet 38, 24-26.

[4] Higgins GA, Jacobsen H (2003) Transgenic mouse models of Alzheimer's disease: Phenotype and application. Behav Pharmacol 14, 419-438.

[5] McGowan E, Eriksen J, Hutton M (2006) A decade of modeling Alzheimer's disease in transgenic mice. Trends Genet 22, 281-289.
[6] Wilcock DM (2010) The usefulness and challenges of transgenic mouse models in the study of Alzheimer's disease. CNS Neurol Disord Drug Targets 9, 386-394.

[7] O'Brein JT, Desmond P, Ames D, Schweitzer I, Chiu E, Tress B (1997) Temporal lobe magnetic resonance imaging can differentiate Alzheimer's disease from normal ageing, depression, vascular dementia and other causes of cognitive impairment. Psychol Med 27, 1267-1275.

[8] Petrella JR, Coleman RE, Doraiswamy PM (2003) Neuroimaging and early diagnosis of Alzheimer disease: A look to the future. Radiology 226, 315-336.

[9] Mosconi L, Brys M, Glodzik-Sobanska L, De Santi S, Rusinek H, de Leon MJ (2007) Early detection of Alzheimer's disease using neuroimaging. Exp Gerontol 42, 129-138.

[10] Thompson PM, Hayashi KM, Dutton RA, Chiang MC, Leow AD, Sowell ER, De Zubicaray G, Becker JT, Lopez OL, Aizenstein HJ, Toga AW (2007) Tracking Alzheimer's disease. Ann N Y Acad Sci 1097, 183-214.

[11] Busatto GF, Diniz BS, Zanetti MV (2008) Voxel-based morphometry in Alzheimer's disease. Expert Rev Neurother 8, 1691-1702.

[12] Leow AD, Yanovsky I, Parikshak N, Hua X, Lee S, Toga AW, Jack CR Jr, Bernstein MA, Britson PJ, Gunter JL, Ward CP, Borowski B, Shaw LM, Trojanowski JQ, Fleisher AS, Harvey D, Kornak J, Schuff N, Alexander GE, Weiner MW, Thompson PM (2009) Alzheimer's disease neuroimaging initiative: A one-year follow up study using tensor-based morphometry correlating degenerative rates, biomarkers and cognition. Neuroimage 45, 645-655.

[13] Budinger TF, Benaron DA, Koretsky AP (1999) Imaging transgenic animals. Annu Rev Biomed Eng 1, 611-648.

[14] Delatour B, Guegan M, Volk A, Dhenain M (2006) In vivo MRI and histological evaluation of brain atrophy in APP/PS1 transgenic mice. Neurobiol Aging 27, 835-847.

[15] Sharief AA, Badea A, Dale AM, Johnson GA (2008) Automated segmentation of the actively stained mouse brain using multi-spectral MR microscopy. Neuroimage 39, 136-145.

[16] Strome EM, Doudet DJ (2007) Animal models of neurodegenerative disease: Insights from in vivo imaging studies. Mol Imaging Biol 9, 186-195.

[17] Choi JK, Jenkins BG, Carreras I, Kaymakcalan S, Cormier K, Kowall NW, Dedeoglu A (2010) Anti-inflammatory treatment in AD mice protects against neuronal pathology. Exp Neurol 223, 377-384.

[18] Van Broeck B, Vanhoutte G, Pirici D, Van Dam D, Wils H, Cuijt I, Vennekens K, Zabielski M, Michalik A, Theuns J, De Deyn PP, Van der Linden A, Van Broeckhoven C, KumarSingh S (2008) Intraneuronal amyloid beta and reduced brain volume in a novel APP T714I mouse model for Alzheimer's disease. Neurobiol Aging 29, 241-252.

[19] Pereira AC, Huddleston DE, Brickman AM, Sosunov AA, Hen R, McKhann GM, Sloan R, Gage FH, Brown TR, Small $\mathrm{SA}$ (2007) An in vivo correlate of exercise-induced neurogenesis in the adult dentate gyrus. Proc Natl Acad Sci US A 104, 5638-5643.

[20] Antequera D, Vargas T, Ugalde C, Spuch C, Molina JA, Ferrer I, Bermejo-Pareja F, Carro E (2009) Cytoplasmic gelsolin increases mitochondrial activity and reduces Abeta burden in a mouse model of Alzheimer's disease. Neurobiol Dis 36, 42-50.

[21] Kurt MA, Davies DC, Kidd M, Duff K, Rolph SC, Jennings KH, Howlett DR (2001) Neurodegenerative changes associated with beta-amyloid deposition in the brains of mice carrying mutant amyloid precursor protein and mutant presenilin-1 transgenes. Exp Neurol 171, 59-71. 
[22] Yang DS, Kumar A, Stavrides P, Peterson J, Peterhoff CM, Pawlik M, Levy E, Cataldo AM, Nixon RA (2008) Neuronal apoptosis and autophagy cross talk in aging PS/APP mice, a model of Alzheimer's disease. Am J Pathol 173, 665-681.

[23] Spuch C, Antequera D, Portero A, Orive G, Hernandez RM, Molina JA, Bermejo-Pareja F, Pedraz JL, Carro E (2010) The effect of encapsulated VEGF-secreting cells on brain amyloid load and behavioral impairment in a mouse model of Alzheimer's disease. Biomaterials 31, 5608-5618.

[24] Holcomb L, Gordon MN, McGowan E, Yu X, Benkovic S, Jantzen P, Wright K, Saad I, Mueller R, Morgan D, Sanders S, Zehr C, O'Campo K, Hardy J, Prada CM, Eckman C, Younkin S, Hsiao K, Duff K (1998) Accelerated Alzheimer-type phenotype in transgenic mice carrying both mutant amyloid precursor protein and presenilin 1 transgenes. Nat Med 4, 97-100.

[25] Van Putten HP, Bouwhuis MG, Muizelaar JP, Lyeth BG, Berman RF (2005) Diffusion-weighted imaging of edema following traumatic brain injury in rats: Effects of secondary hypoxia. J Neurotrauma 22, 857-872.

[26] Franklin K, Paxinos G (1997) The Mouse Brain in Stereotaxic Coordinates, Academic Press, San Diego.

[27] Provencher SW (1993) Estimation of metabolite concentrations from localized in vivo proton NMR spectra. Magn Reson Med 30, 672-679.

[28] Hosmer DW, Lemeshow S (2001) Applied logistic regression (Wiley Series in probability and statistics), John Wiley, New York.

[29] Webster B, Hansen L, Adame A, Crews L, Torrance M, Thal L, Masliah E (2006) Astroglial activation of extracellularregulated kinase in early stages of Alzheimer disease. $J$ Neuropathol Exp Neurol 65, 142-151.

[30] Bradley KM, Bydder GM, Budge MM, Hajnal JV, White SJ, Ripley BD, Smith AD (2002) Serial brain MRI at 3-6 month intervals as a surrogate marker for Alzheimer's disease. $\mathrm{Br} \mathrm{J}$ Radiol 75, 506-513.

[31] de Leon MJ, Mosconi L, Blennow K, DeSanti S, Zinkowski R, Mehta PD, Pratico D, Tsui W, Saint Louis LA, Sobanska L, Brys M, Li Y, Rich K, Rinne J, Rusinek H (2007) Imaging and CSF studies in the preclinical diagnosis of Alzheimer's disease. Ann N Y Acad Sci 1097, 114-145.

[32] Lee JY, Friedman JE, Angel I, Kozak A, Koh JY (2004) The lipophilic metal chelator DP-109 reduces amyloid pathology in brains of human beta-amyloid precursor protein transgenic mice. Neurobiol Aging 25, 1315-1321.

[33] Wengenack TM, Jack CR Jr, Garwood M, Poduslo JF (2008) MR microimaging of amyloid plaques in Alzheimer's disease transgenic mice. Eur J Nucl Med Mol Imaging 35(Suppl 1), S82-S88.

[34] Yang D, Xie Z, Stephenson D, Morton D, Hicks CD, Brown TM, Sriram R, O’Neill S, Raunig D, Bocan T (2011) Volumetric MRI and MRS provide sensitive measures of Alzheimer's disease neuropathology in inducible Tau transgenic mice (rTg4510). Neuroimage 54, 2652-2658.

[35] Lau JC, Lerch JP, Sled JG, Henkelman RM, Evans AC, Bedell BJ (2008) Longitudinal neuroanatomical changes determined by deformation-based morphometry in a mouse model of Alzheimer's disease. Neuroimage 42, 19-27.

[36] Marjanska M, Curran GL, Wengenack TM, Henry PG, Bliss RL, Poduslo JF, Jack CR Jr, Ugurbil K, Garwood M (2005) Monitoring disease progression in transgenic mouse models of Alzheimer's disease with proton magnetic resonance spectroscopy. Proc Natl Acad Sci U S A 102, 11906-11910.

[37] von Kienlin M, Kunnecke B, Metzger F, Steiner G, Richards JG, Ozmen L, Jacobsen H, Loetscher H (2005) Altered metabolic profile in the frontal cortex of PS2APP transgenic mice, monitored throughout their life span. Neurobiol Dis 18, 32-39.

[38] Nestor SM, Rupsingh R, Borrie M, Smith M, Accomazzi V, Wells JL, Fogarty J, Bartha R (2008) Ventricular enlargement as a possible measure of Alzheimer's disease progression validated using the Alzheimer's disease neuroimaging initiative database. Brain 131, 2443-2454.

[39] Jack CR Jr, Shiung MM, Gunter JL, O'Brien PC, Weigand SD, Knopman DS, Boeve BF, Ivnik RJ, Smith GE, Cha RH, Tangalos EG, Petersen RC (2004) Comparison of different MRI brain atrophy rate measures with clinical disease progression in AD. Neurology 62, 591-600.

[40] Ridha BH, Anderson VM, Barnes J, Boyes RG, Price SL, Rossor MN, Whitwell JL, Jenkins L, Black RS, Grundman M, Fox NC (2008) Volumetric MRI and cognitive measures in Alzheimer disease: Comparison of markers of progression. J Neurol 255, 567-574.

[41] Silbert LC, Quinn JF, Moore MM, Corbridge E, Ball MJ, Murdoch G, Sexton G, Kaye JA (2003) Changes in premorbid brain volume predict Alzheimer's disease pathology. Neurology 61, 487-492.

[42] Xie Z, Yang D, Stephenson D, Morton D, Hicks C, Brown T, Bocan T (2010) Characterizing the regional structural difference of the brain between tau transgenic (rTg4510) and wild-type mice using MRI. Med Image Comput Comput Assist Interv 13, 308-315.

[43] Chen CC, Tung YY, Chang C (2011) A lifespan MRI evaluation of ventricular enlargement in normal aging mice. Neurobiol Aging 32, 2299-2307.

[44] Redwine JM, Kosofsky B, Jacobs RE, Games D, Reilly JF, Morrison JH, Young WG, Bloom FE (2003) Dentate gyrus volume is reduced before onset of plaque formation in PDAPP mice: A magnetic resonance microscopy and stereologic analysis. Proc Natl Acad Sci U S A 100, 1381-1386.

[45] Oberg J, Spenger C, Wang FH, Andersson A, Westman E, Skoglund P, Sunnemark D, Norinder U, Klason T, Wahlund LO, Lindberg M (2008) Age related changes in brain metabolites observed by $1 \mathrm{H}$ MRS in APP/PS1 mice. Neurobiol Aging 29, 1423-1433.

[46] Maheswaran S, Barjat H, Rueckert D, Bate ST, Howlett DR, Tilling L, Smart SC, Pohlmann A, Richardson JC, Hartkens T, Hill DL, Upton N, Hajnal JV, James MF (2009) Longitudinal regional brain volume changes quantified in normal aging and Alzheimer's APP $\times$ PS1 mice using MRI. Brain Res $\mathbf{1 2 7 0}$, 19-32.

[47] Kabani NJ, Sled JG, Chertkow H (2002) Magnetization transfer ratio in mild cognitive impairment and dementia of Alzheimer's type. Neuroimage 15, 604-610.

[48] Hanyu H, Asano T, Iwamoto T, Takasaki M, Shindo H, Abe K (2000) Magnetization transfer measurements of the hippocampus in patients with Alzheimer's disease, vascular dementia, and other types of dementia. AJNR Am J Neuroradiol 21, 1235-1242.

[49] Hanyu H, Asano T, Sakurai H, Takasaki M, Shindo H, Abe K (2001) Magnetization transfer measurements of the hippocampus in the early diagnosis of Alzheimer's disease. $J$ Neurol Sci 188, 79-84.

[50] van der Flier WM, van den Heuvel DM, WeverlingRijnsburger AW, Bollen EL, Westendorp RG, van Buchem MA, Middelkoop HA (2002) Magnetization transfer imaging in normal aging, mild cognitive impairment, and Alzheimer's disease. Ann Neurol 52, 62-67.

[51] van Buchem MA, Tofts PS (2000) Magnetization transfer imaging. Neuroimaging Clin N Am 10, 771-788, ix. 
[52] Ridha BH, Symms MR, Tozer DJ, Stockton KC, Frost C, Siddique MM, Lewis EB, MacManus DG, Boulby PA, Barker GJ, Rossor MN, Fox NC, Tofts PS (2007) Magnetization transfer ratio in Alzheimer disease: Comparison with volumetric measurements. AJNR Am J Neuroradiol 28, 965-970.

[53] Gass A, Niendorf T, Hirsch JG (2001) Acute and chronic changes of the apparent diffusion coefficient in neurological disorders-biophysical mechanisms and possible underlying histopathology. J Neurol Sci 186(Suppl 1), S15-S23.

[54] Thiessen JD, Glazner KA, Nafez S, Schellenberg AE, Buist R, Martin M, Albensi BC (2010) Histochemical visualization and diffusion MRI at 7 Tesla in the TgCRND8 transgenic model of Alzheimer's disease. Brain Struct Funct 215, 29-36.

[55] Miller BL, Moats RA, Shonk T, Ernst T, Woolley S, Ross BD (1993) Alzheimer disease: Depiction of increased cerebral myo-inositol with proton MR spectroscopy. Radiology 187, 433-437.

[56] Moats RA, Ernst T, Shonk TK, Ross BD (1994) Abnormal cerebral metabolite concentrations in patients with probable Alzheimer disease. Magn Reson Med 32, 110-115.

[57] Shonk TK, Moats RA, Gifford P, Michaelis T, Mandigo JC, Izumi J, Ross BD (1995) Probable Alzheimer disease: Diagnosis with proton MR spectroscopy. Radiology 195, 65-72.

[58] Ross BD, Bluml S, Cowan R, Danielsen E, Farrow N, Tan $\mathrm{J}$ (1998) In vivo MR spectroscopy of human dementia. Neuroimaging Clin N Am 8, 809-822.

[59] Jessen F, Traeber F, Freymann N, Maier W, Schild HH, Heun R, Block W (2005) A comparative study of the different $\mathrm{N}$-acetylaspartate measures of the medial temporal lobe in Alzheimer's disease. Dement Geriatr Cogn Disord 20, 178183.

[60] Kantarci K, Petersen RC, Boeve BF, Knopman DS, TangWai DF, O'Brien PC, Weigand SD, Edland SD, Smith GE, Ivnik RJ, Ferman TJ, Tangalos EG, Jack CR Jr (2004) 1H MR spectroscopy in common dementias. Neurology 63, 1393 1398.

[61] Valenzuela MJ, Sachdev P (2001) Magnetic resonance spectroscopy in AD. Neurology 56, 592-598.

[62] Wang Z, Zhao C, Yu L, Zhou W, Li K (2009) Regional metabolic changes in the hippocampus and posterior cingulate area detected with 3-Tesla magnetic resonance spectroscopy in patients with mild cognitive impairment and Alzheimer disease. Acta Radiol 50, 312-319.

[63] den Heijer T, Sijens PE, Prins ND, Hofman A, Koudstaal PJ, Oudkerk M, Breteler MM (2006) MR spectroscopy of brain white matter in the prediction of dementia. Neurology $\mathbf{6 6}$, 540-544.

[64] Kantarci K, Lowe V, Przybelski SA, Senjem ML, Weigand SD, Ivnik RJ, Roberts R, Geda YE, Boeve BF, Knopman DS, Petersen RC, Jack CR Jr (2011) Magnetic resonance spectroscopy, beta-amyloid load, and cognition in a population-based sample of cognitively normal older adults. Neurology 77, 951-958.

[65] Donovan MH, Yazdani U, Norris RD, Games D, German DC, Eisch AJ (2006) Decreased adult hippocampal neurogenesis in the PDAPP mouse model of Alzheimer's disease. J Comp Neurol 495, 70-83.

[66] Lopez-Toledano MA, Shelanski ML (2007) Increased neurogenesis in young transgenic mice overexpressing human APP(Sw, Ind.). J Alzheimers Dis 12, 229-240.

[67] Perez-Gonzalez R, Antequera D, Vargas T, Spuch C, Bolos M, Carro E (2011) Leptin induces proliferation of neuronal progenitors and neuroprotection in a mouse model of Alzheimer's disease. J Alzheimers Dis 24(Suppl 2), 17-25.

[68] Jin K, Peel AL, Mao XO, Xie L, Cottrell BA, Henshall DC, Greenberg DA (2004) Increased hippocampal neurogenesis in Alzheimer's disease. Proc Natl Acad Sci U S A 101, 343-347.

[69] Wurtman RJ, Blusztajn JK, Maire JC (1985) "Autocannibalism" of choline-containing membrane phospholipids in the pathogenesis of Alzheimer's disease-A hypothesis. Neurochem Int 7, 369-372.

[70] Westman E, Spenger C, Oberg J, Reyer H, Pahnke J, Wahlund LO (2009) In vivo 1H-magnetic resonance spectroscopy can detect metabolic changes in APP/PS1 mice after donepezil treatment. BMC Neurosci 10, 33.

[71] Bartha R, Smith M, Rupsingh R, Rylett J, Wells JL, Borrie MJ (2008) High field (1)H MRS of the hippocampus after donepezil treatment in Alzheimer disease. Prog Neuropsychopharmacol Biol Psychiatry 32, 786-793. 